\title{
Fixação interna de fratura de epífise proximal de tíbia em potro
}

\author{
Internal fixation of the tibial proximal epiphyses fracture in a foal
}

\author{
Carlos Henrique Maciel Brunner ${ }^{1}$ João Paulo Boccia ${ }^{2}$ Maria de Fátima Monteiro Martins ${ }^{2}$

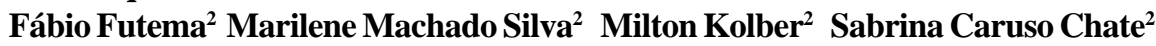 \\ José Jofre Martins Bayeux ${ }^{3}$
} \begin{abstract}
A fratura Salter Harris tipo II ocorre comumente
na epífise proximal de tíbia em potros e tem reparação difícil
mas com o advento das técnicas de fixação interna, o
prognóstico tem melhorado. No caso descrito, em um potro
da raça árabe de 26 dias de idade, com fratura proximal de
tíbia direita tipo Salter Harris II, foram utilizadas as placas
de compressão para garantirem estabilização e aproximação
dos fragmentos fraturados, porém com risco de ocasionar
distúrbios no desenvolvimento esquelético. No caso relatado,
através do controle radiológico, não foi evidenciada
diminuição da radioluscência na região correspondente à
cartilagem de conjugação proximal da tíbia. O artigo tem
como objetivo discutir o tratamento empregado que se mostrou
como alternativa viável pelo resultado favorável com bons
resultados. RESUMO
\end{abstract}

Palavras chave: fratura, epífise, tíbia, potro.

\section{ABSTRACT}

The most frequent fracture is tibia's proximal epiphysis in foals is Salter Harris type II although its difficult to repair. The development of the inner fixation technique has been made the prognosis better. The dynamic compression bone plate allow guaranteed reduction and stabilization of the bone's fragments, but it can promote development disturbs. In this case, by the radiological control, it has not shown less radiolucency in the proximal tibia's growth plate. The treatment used showed itself as a feasible alternative because of the favourable good results.

Key words: fracture, epiphysis, tibia, foal.
A fratura mais comum na região da placa epifisária de crescimento proximal da tíbia (EMBERTSON et al., 1986a; WAGNER et al., 1984; WHITE et al., 1982) é a Salter-Harris tipo II. A solução de continuidade passa pela placa de crescimento e propaga-se no sentido medial e se estende lateralmente formando um fragmento triangular na metáfise (WAGNER et al., 1984; WHITE et al., 1982). Essa conformação particular de fratura resulta de traumas na face lateral do membro (EMBERTSON et al., 1986a; WAGNER et al., 1984). A força de tensão na fise da face medial do osso causa separação direta e contrapõe-se à força original na face lateral, produzindo a fratura e provocando desvio medial do membro (WAGNER et al., 1984).

O tratamento cirúrgico com o uso de várias técnicas de fixação tem sido descrito na literatura e reportado em vários trabalhos. Os métodos de fixação incluem o uso de pinos transversos (aparato Charnley), fixação por pinos cruzados, fixação através de parafusos, e placas. Todas essas técnicas têm sido usadas e podem ser consideradas como opções viáveis na reparação dessas lesões.

O objetivo desta nota é discutir a utilização de uma placa de compressão no tratamento de um potro com fratura proximal de tíbia tipo Salter Harris II.

'Curso de Medicina Veterinária (CMV) da Universidade Paulista (UNIP), Rua Tenente Julio Prado Neves 965, 02370-000, São Paulo, SP, Brasil, e-mail: carlosbrunner@uol.com.br (autor para correspondência)

${ }^{2} \mathrm{MV}$, UNIP, São Paulo, SP, Brasil;

${ }^{3}$ Médico Veterinário Autônomo, São Paulo, SP, Brasil; 
Um potro da raça árabe de 26 dias de idade, macho, pesando $55 \mathrm{~kg}$, foi encaminhado ao Hospital Veterinário com histórico de aumento de volume no membro posterior direito na região da articulação fêmur-tibio-patelar, desvio medial e disfunção do membro há seis dias.

À palpação da região, observou-se aumento de volume de consistência mista de firme a pastosa, com sensibilidade e aumento de temperatura locais. Apesar da disfunção do membro, o animal mantinhase em estação e mamava normalmente. O hemograma revelou leucocitose por neutrofilia e macrocitose discreta na série eritrocitária. $\mathrm{O}$ exame radiológico revelou fratura completa e fechada envolvendo a fise e epífise proximal da tíbia do membro posterior direito, completa, fechada em terço proximal da tíbia com desvio do eixo anatômico do tipo Salter-Harris II (Figura 1).

$\mathrm{O}$ animal foi encaminhado à cirurgia para realização de osteossíntese com placa e parafusos. A cirurgia foi realizada sob anestesia geral, sendo a préanestesia realizada com romifidina na dose de $40 \mathrm{mcg}$ $\mathrm{kg}^{-1}$, via intravenosa (IV), a indução com a associação de quetamina ( $2 \mathrm{mg} \mathrm{kg}^{-1}$, IV) e midazolan $\left(0,3 \mathrm{mg} \mathrm{kg}^{-1}\right.$, IV) e a manutenção com halotano. Após a preparação do membro, o acesso cirúrgico foi realizado pela face medial da região tibial proximal com o animal em decúbito lateral direito. Os fragmentos menores foram removidos e uma placa reta estreita de compressão dinâmica, após ter sido moldada ao contorno ósseo, foi fixada com quatro parafusos corticais e um esponjoso de $4,5 \mathrm{~mm}$. A síntese dos tecidos moles foi realizada com fio de ácido poliglicólico 2-0 e náilon monofilamento 2-0.

Durante o período pós-operatório, o animal foi tratado com ceftiofur sódico $2,2 \mathrm{mg} \mathrm{kg}^{-1}$ intramuscular (IM), SID; cetoprofeno $10 \% 2,2 \mathrm{mg} \mathrm{kg}^{-1}$ IM, SID e cimetidina $6,6 \mathrm{mg} \mathrm{kg}^{-1}$ via oral, TID. Houve drenagem de secreção purulenta por dois orifícios de pontos distais, sendo coletado material para cultura e antibiograma. A cultura revelou a presença de Staphylococcus sp, sensível à gentamicina que foi administrada na dose de $6,6 \mathrm{mg} \mathrm{kg}^{-1} \mathrm{IM}$, SID conjuntamente ao ceftiofur, tratamento continuado por 15 dias.

Após cinco dias da cirurgia, o potro apresentava apoio satisfatório do membro acometido (Figura 2).

Após 10 dias, foram removidos os pontos. Em 21 dias, a ferida cicatrizou por completo, havendo nesse período diminuição gradual de volume e temperatura locais com apoio total do membro afetado; ao exame radiográfico notava-se ainda evidente linha de fratura com reação proliferativa de formação de calo ósseo, presença de desvio lateral discreto da tíbia correspondente, não havendo sinais radiográficos de lise óssea junto aos parafusos implantados com preservação do eixo anatômico.

Decorridos 40 dias, verificou-se formação do calo ósseo e eixo anatômico em posição adequada com preservação da linha de crescimento, o que possibilitou a remoção cirúrgica da placa e parafusos(Figura 3).

Vários fatores devem ser considerados quando se estima o prognóstico em casos de fratura epifisária. Eles incluem o tipo de fratura fiseal, a severidade do trauma, a integridade da vascularização da epífise, movimentação epifisária, se a fratura é aberta ou fechada, idade do indivíduo, tempo de fratura antes do tratamento, o método e a exatidão da redução e estabilização (EMBERTSON et al., 1986b). Em termos gerais, as fraturas na tíbia têm uma reparação difícil, muitas vezes associada com complicações que contribuem para uma pequena taxa de sucesso (McDUFFEE et al., 1997). Com o advento das placas de compressão dinâmica e técnicas de fixação interna, o prognóstico dessas fraturas tem sido melhor em potros (SASAKI et al., 1998; McDUFFEE et al., 1997; BERTONE, 1994). Essas placas garantem estabilização suficiente, neutralizando as forças compressivas e de angulação, mas não as forças de torção (McDUFFEE et al., 1997; EASTER et al., 1994).

A fixação da fratura por meio de placa tende a garantir estabilização dos fragmentos fraturados, porém em animais em fase de crescimento poderia ocasionar distúrbios de desenvolvimento. A placa fixada na face medial da tíbia impede o crescimento criando condições favoráveis à formação de desvio tipo varus. No animal relatado, essa possibilidade foi prevista antes da cirurgia, pois os parafusos foram colocados na epífise proximal e metáfise da tíbia comprimindo a cartilagem de conjugação na sua face medial.

WHITE et al.(1982) relataram que a placa para osteossíntese forma uma ponte transfiseal quando utilizada para correção de fratura tibial proximal. Segundo os mesmos autores, esse procedimento não só imobiliza o foco de fratura, mas também permite um crescimento mais rápido da face lateral do osso, corrigindo o alinhamento axial. A região lateral não necessita de placa de fixação, pois a tensão necessária é feita pelo aparato músculo tendíneo lateral.

No potro em descrição, dois parafusos atravessaram a cartilagem de conjugação para aproximar e fixar a epífise proximal, criando expectativa de ossificação precoce do disco epifisário, estimulada por um processo inflamatório ocasionado pelos parafusos. Os controles radiológicos realizados posteriormente à 


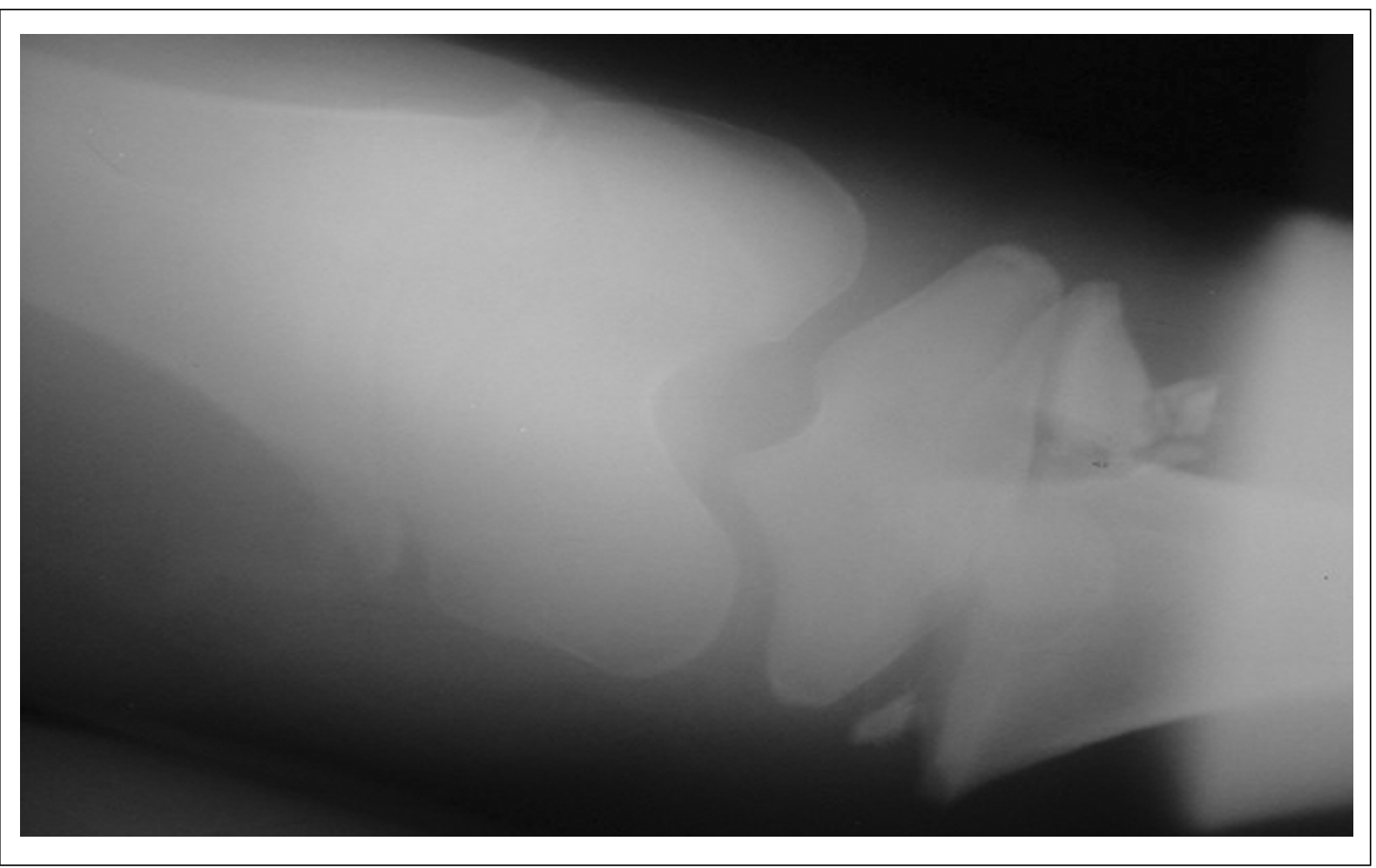

Figura 1 - Radiografia crânio caudal da articulação fêmur-tíbio-patelar direita de um potro árabe, pesando 55kg.

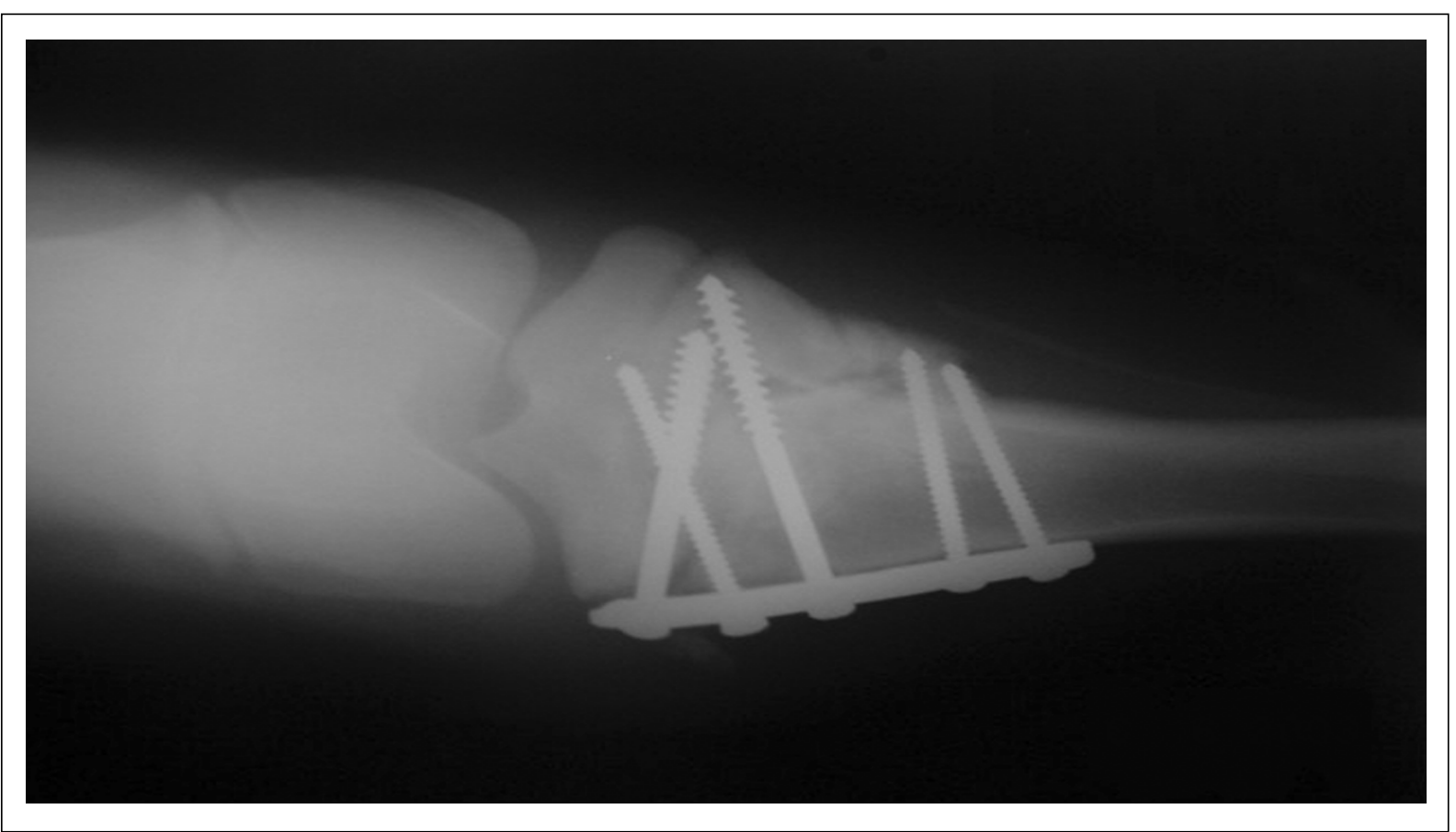

Figura 2 - Radiografia crânio caudal da articulação fêmur-tíbio-patelar direita com cinco dias da redução da fratura em um potro árabe de $55 \mathrm{~kg}$.

Ciência Rural, v.36, n.1, jan-fev, 2006. 


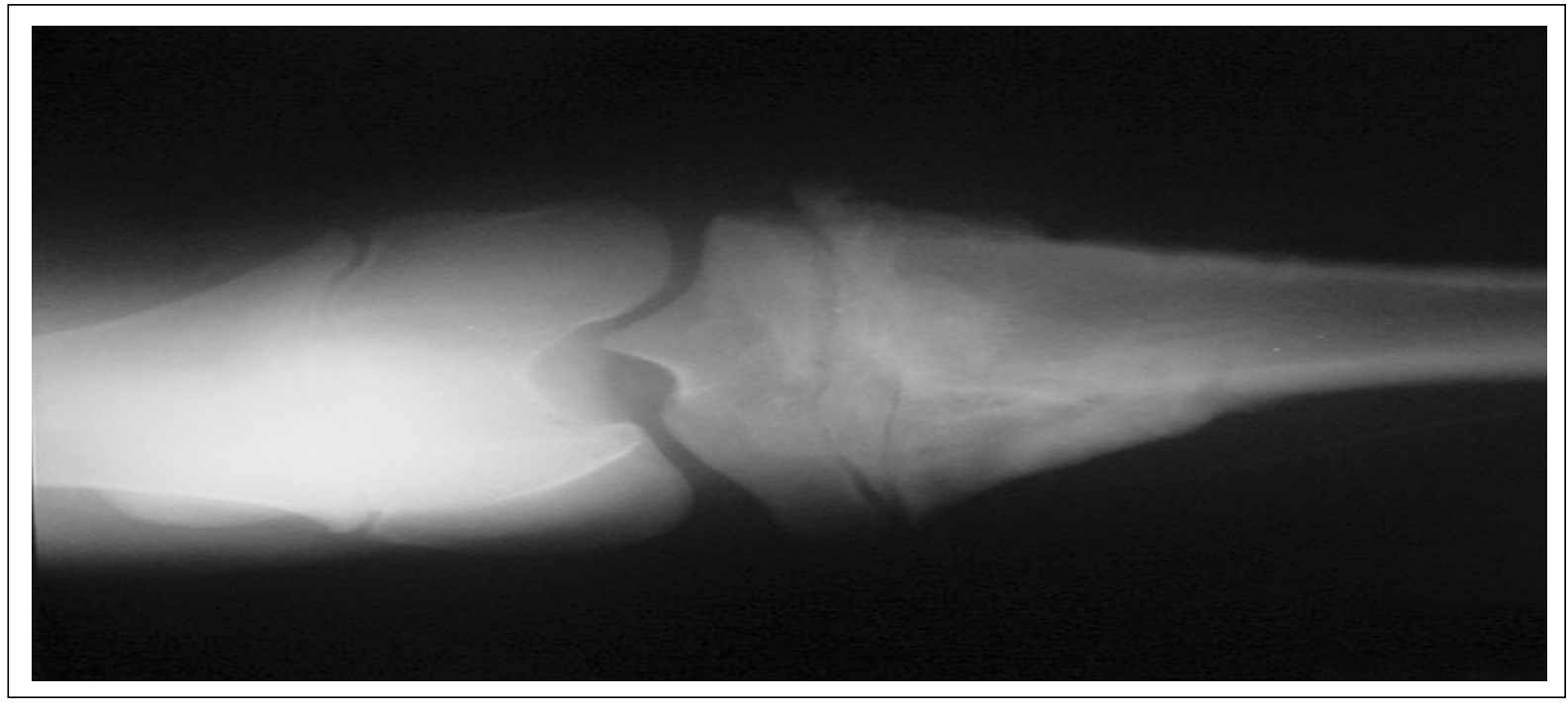

Figura 3 - Radiografia crânio caudal da articulação fêmur- tíbio- patelar direita com 40 dias de redução da fratura em um potro árabe.

colocação da placa não demonstraram diminuição de radioluscência na região correspondente à cartilagem de conjugação proximal da tíbia, significativa em um processo de fechamento precoce do disco de crescimento ósseo da região. WAGNER et al. (1984) relataram que, se o suprimento vascular epifiseal e a camada germinativa de condrócitos forem mantidos, não há retardo no crescimento ósseo, mesmo se forem aplicados parafusos atravessando a placa de crescimento. Da mesma forma, não há desvio angular do eixo ósseo pela fixação por placa apenas da face medial da tíbia.

Na metáfise, houve proliferação periostal na face lateral na qual ocorreu exposição da extremidade de dois parafusos mais distais em tecido mole. Esse crescimento ósseo permitiu maior sustentação ao fragmento lateral, fixado pelos parafusos, e possivelmente tenha sido estimulado pelas próteses e alinhados por forças vetoriais de compressão no local.

Não foi feita imobilização com gesso, pois isto poderia provocar ainda mais lesões por fornecer apoio principalmente na região distal à fratura e servindo como ponto de apoio de uma alavanca durante a movimentação da articulação fêmur tíbio patelar. Também se descartou a utilização de aparelho fixador externo por meio de pinos Steinmann, dada a dificuldade em transfixar a epífise envolvendo o fragmento destacado da tíbia e também o risco de infecção pelos pinos que atravessam a pele, desnecessário para uma fratura fechada.

A técnica de pinos de Steinmann implantados de forma cruzada sobre os fragmentos pode ser empregada para fratura epifiseais de tíbia (WATKINS, 1996), porém não foi a técnica de escolha por ser uma fratura Salter Harris II em que o fragmento destacado não sofreria força de tração pelos pinos.

O tratamento empregado mostrou-se eficaz para a fratura e foi facilitado pela precocidade com que foi realizado, pela idade do animal e ainda pela índole do potro que facilitava o manejo. Embora não tenha sido encontrada explicação objetiva para a ausência de adversidades como desvio varus ou fechamento precoce do disco epifisário, a correção da fratura Salter Harris II na tíbia por meio de placa de compressão e parafusos evidenciou-se como alternativa viável para potros pelo resultado obtido.

\section{REFERÊNCIAS}

BERTONE, A.L. Management of orthopedic emergencies Veterinary Clinics of North America: Equine Practice, Orlando, v.10, n.3, p.603-625, 1994

EASTER, J.L. et al. Transfixation cast repair of an open cannon bone fracture in a foal. Equine Practice, Montreal, v.16, n.10, p.16-23, 1994.

EMBERTSON, R.M. et al. Physeal fractures in the horse I.Classification and iIncidence. Veterinary Surgery, Philadelphia, v.15, n.3, p.223-229, 1986a.

EMBERTSON, R.M. et al. Physeal fractures in the horse. II.Management and outcome. Veterinary Surgery, Philadelphia, v.15, n.3, p.230-236, 1986 b.

McDUFFEE, L.A. et al. An in vitro biomechanical investigation of the mechanical properties of dynamic compression plated osteotomized adult equine tibiae. Veterinary Surgery, Philadelphia, v.26, p.126-136, 1997. 
SASAKI, N. et al. Double DCP fixation for the spiral tibial fracture of a Racehorse. Journal Equine Science, Tokyo, v.9, n.2, p.71-75, 1998.

WAGNER, P.C. et al. Cancellous bone screws for repair of proximal growth plate fractures of the tibia in foals. Journal American Veterinary Medical Association, Schaumburg, v.184, n.6, p.688-691, 1984.
WATKINS, J.P. Fractures of the tibia. In: NIXON, A.J. Equine fracture repair. 3.ed. Philadelphia: Saunders, 1996. p. 275-276.

WHITE, N.A. et al. Use of bone plate for repair of proximal physeal fractures of the tibia in two foals. Journal American Veterinary Medical Association, Schaumburg, v.181, n.3, p.252-254, 1982. 